\title{
The impact of training traditional birth attendants on the utilisation of maternal health services
}

\author{
H. N. MATHUR, DAMODAR, AND P. N. SHARMA \\ From the RNT Medical College, Udaipur, India
}

T. P. JAIN

From the SMS Medical College, Jaipur, India

SUMMARY The impact of training traditional birth attendants (TBAs) on the utilisation of $\vec{\circ}$ maternal health services at a rural health training centre in India has been studied. Records of the $\vec{\omega}$ utilisation of the services for two periods of six months each (one before training and one after) $\frac{\sigma}{\circ}$

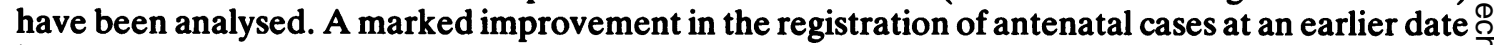
in pregnancy has been observed. The average number of visits to antenatal clinics, the $\dot{\omega}$ immunisation against tetanus, and the presence of trained personnel at the time of delivery att ${ }_{i}^{\omega}$ showed considerable improvement after the local TBAs had been trained and motivated. The differences observed in the two series were statistically significant.

Midwifery services in India are far from satisfactory. Mostly these services are provided by traditional birth attendants (TBAs) who carry on this profession as a family right. Poor utilisation of the available maternal health services, which are still scarce, makes things worse. There are various reasons why people do not use the available services, among which lack of awareness and confidence are important. The TBA is often the one person who caters for the maternal health needs of our community and although untrained and illiterate she enjoys the confidence of the masses. Therefore, motivation and training of TBAs might go a long way towards improving the take-up of maternal health services in rural areas. An attempt was therefore made to review the utilisation of maternal health services available at the Rural Health Training Centre, Vallabh Nagar, attached to the RNT Medical College, Udaipur, before and after the start of TBA training courses.

\section{Material and methods}

The records were analysed of the maternal health services at the Rural Health Training Centre, Vallabh Nagar, for two periods of six months each-one before the start of TBA training (March 1977 to August 1977: Period I) and the other after training (December 1977 to May 1978: Period II). The training period was September to November
1977. All factors of manpower were identical in the two periods except the trained and motivated TBA? A total of 10 TBAs working in the village of Vallabi Nagar (population 4500) and belonging to differe cै castes were trained in accordance with the Government of India's instructions.

\section{Results}

Eighty-two deliveries occurred in Period I (before the start of TBA training) and 38 women (46\%) had registered with the antenatal clinic of the centre. Sixty-four deliveries occurred in Period II (after training) and 45 women (70\%) had registered (Figure). The difference was found to be significant statistically $(P<0.005)$.

In Period I, 130 pregnant women registered at the clinic, of whom $11(8 \%)$ were brought by the TBA; in the second period 107 pregnant women were registered, of whom $19(18 \%)$ were brought by the TBA. The difference was significant statistically $(\mathrm{P}<0.05)$.

Table 1 reports the duration of amenorrhoea at the first visit of the registered women in the two periods. $N$ Twenty-five cases were registered at the clinic after the 32nd week of gestation in the first period, but 0 only three cases in the second period. The difference $\mathrm{C}$ was highly significant $(P<0.001)$.

The average number of visits to the antenatal clinic 
Table 1 Duration of amenorrhea at first visit by pregnant women

\begin{tabular}{lllllll}
\hline & \multicolumn{2}{l}{ Duration (weeks) } & & & \\
\cline { 2 - 6 } & $<12$ & $12-24$ & $24-28$ & $28-32$ & $32+$ & All cases \\
\hline Period I & 10 & 32 & 30 & 33 & 25 & 130 \\
Period II & 41 & 25 & 18 & 20 & 3 & 107 \\
Both periods & 51 & 57 & 48 & 53 & 28 & 237 \\
\hline
\end{tabular}

$x^{2}=48.44 \quad$ df $=4 \quad P=<0.001$

Table 2 Number of visits by pregnant women to the antenatal clinic

\begin{tabular}{lllllllllll}
\hline & \multicolumn{2}{l}{ No. of visits } & & & & \\
\cline { 2 - 9 } & 1 & 2 & 3 & 4 & 5 & 6 & $7+$ & Total & Mean \\
\hline Period I & 64 & 33 & 10 & 11 & 2 & 4 & 6 & 130 & $2 \cdot 23$ \\
Period II & 14 & 12 & 33 & 21 & 10 & 10 & 7 & 107 & 3.55 & \\
\hline
\end{tabular}

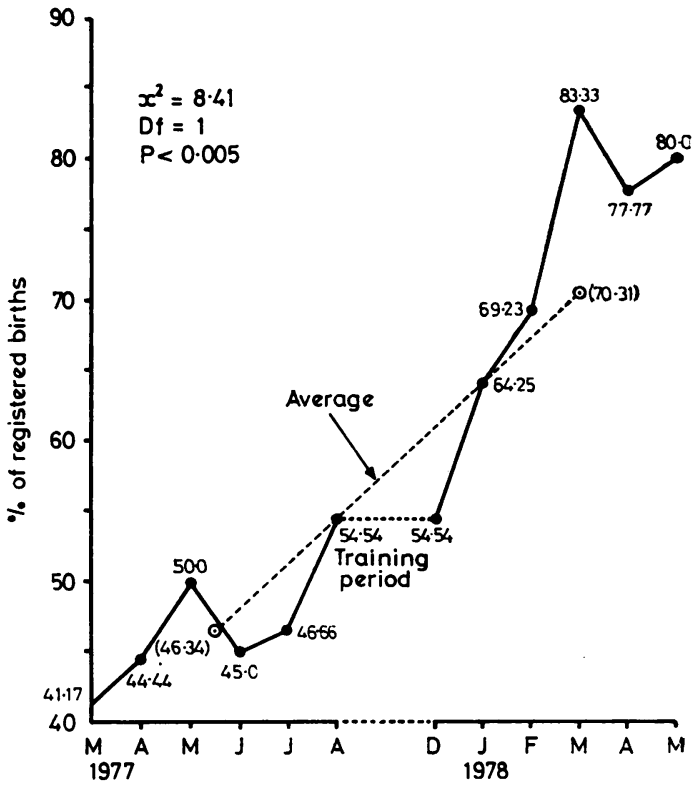

Figure Registration of women at the antenatal centre.

in Period I and Period II were 2.23 and 3.55 respectively (Table 2 ). This difference was significant $(\mathrm{P}<0 \cdot 01)$.

In Period I, of the 130 women registered, $26(20 \%)$ did not agree to tetanus toxoid injection even after great persuasion by the hospital staff. However, when TBAs were taken into confidence, only eight women out of $107(7 \%)$ did not agree to tetanus toxoid. Similarly, the performance of complete immunisation was better after the involvement of TBAs (Table 3).

In Period I, the hospital staff were called for assistance in only three deliveries. Two of these were
Table 3 Tetanus immunisation of pregnant women

\begin{tabular}{llccl}
\hline & Refusals & $\begin{array}{l}\text { One } \\
\text { dose only }\end{array}$ & $\begin{array}{l}\text { Two } \\
\text { doses }\end{array}$ & Total \\
\hline Period I & 26 & 57 & 47 & 130 \\
& $(20 \%)$ & $(44 \%)$ & $(36 \%)$ & \\
\hline Period II & $\begin{array}{c}8 \\
(7 \%)\end{array}$ & $\begin{array}{c}43 \\
(40 \%)\end{array}$ & $\begin{array}{c}56 \\
(52 \%)\end{array}$ & 107 \\
\hline Total & 34 & 100 & 103 & 237 \\
\hline$x^{2}=10.07$ & df $=2$ & $P=<0.01$ & &
\end{tabular}

breech presentations and one was a twin pregnancy. In Period II, the hospital staff were called seven times and on five of these occasions the deliveries were normal. The assistance of a doctor was sought in two cases-one for breech presentation and the other for cord-prolapse which was delivered by the doctor at home as a stillbirth.

\section{Discussion}

Increasing the input does not necessarily improve the output. There is no doubt that since Independence the medical and health services in India have improved both quantitatively and qualitatively, yet even today, the Indian masses have faith in the local TBA. Medical institutions and personnel have also been made available to remote villages, yet it must be accepted that they have, to a large extent, failed to win the confidence and trust of the masses. Almost all deliveries are conducted by the local TBA in rural, semi-urban, and even urban areas, and the people seek hospital assistance only when there are complications. In the present study the local TBAs performed $90 \%$ of the deliveries which took place. In Ghana, $75 \%$ of all deliveries are either unattended or 
Table 4 Comparison between this study and that of Sapru et al. (1974) in Delhi

\begin{tabular}{|c|c|c|c|c|}
\hline \multirow[b]{2}{*}{ Measure of use of service } & & \multicolumn{2}{|l|}{ This study } & \multirow[b]{2}{*}{ Delhi study } \\
\hline & & Period I & Period II & \\
\hline Percentage of deliveries in registered women & & $\begin{array}{l}\% \\
46\end{array}$ & $\begin{array}{l}\% \\
70\end{array}$ & $\begin{array}{l}\% \\
73\end{array}$ \\
\hline \multirow[t]{3}{*}{ Time of registration } & I Trimester & 8 & 38 & 8 \\
\hline & II Trimester & 25 & 23 & 63 \\
\hline & III Trimester & 68 & 38 & 27 \\
\hline Average no. of visits by an antenatal case & & 2 & 4 & 4 \\
\hline Complete tetanus immunisation & & 36 & 52 & 9 \\
\hline
\end{tabular}

attended by untrained personnel such as relatives or TBAs (Nicholas et al., 1976).

It is useless to blame the local TBA for the complications of mishandled deliveries, because she has never had the opportunity to be trained by qualified personnel. On the contrary, her efforts should be acknowledged with gratitude, because she is catering for a great health need and working in most unfavourable conditions. From her experience in attending deliveries for many years, she has acquired a self-confidence which is very important. It is worthwhile to make use of her self-confidence and the trust that she enjoys from the public to increase the utilisation of maternal health services. In our study we found that if the TBAs were trained and sufficiently motivated, utilisation improved. Table 4 shows the change brought about by the involvement of TBAs in our study and compares it with the study of Sapru, Chuttani, and Srivastava (1974).

Bhore (1946) and Mudaliar (1961) have recommended training TBAs as an interim measure to improve the midwifery services in India. Similar measures to tackle a similar state of affairs have also been adopted in various other developing countries like Niger (Kalimo et al., 1975). 'After a short training the TBA becomes the frontline link between the village population and the health services', which would improve the quality of delivery of health services besides minimising the load of complications.

TBAs are generally middle-aged or elderly women. Although they may be illiterate, their confidence gained from long experience, and the public faith in them, have led to the development of self-pride. They would not accept training even with incentives if their self-pride was hurt, nor would their motivation be improved. This is a human factor which must be kept in mind by trainers. The ego of the TBA should be nourished by humorous teaching and by appreciating the knowledge, skill, and self-confidence which she already possesses.

\section{Conclusion}

Involvement of local TBAs in the maternal and health services definitely improves the utilisation of these services. Their own confidence and the publie trust in them requires that they should not only be trained but also motivated, so that they activel $\frac{\rho}{\sigma}$ participate in and promote the delivery of preventive maternal health services.

Reprints from Dr. H. N. Mathur, 22 Subhash Nagar, facing BN College, Udaipur, Rajasthan, INDIA 313 001.

\section{References}

Bhore, J. (1946). Report of the Health Survey and Development Committee, 2, 399-402. Ministry of Health: Delhi.

Kalimo, E., Barres, J. F., and Torfs, M. (1975). Meeting basic health needs in developing countries: alternative approaches. WHO Chronicle, 25, 181-182.

Mudaliar, A. L. (1961). Report of the Health Survey and Planning Committee, 1, 372-373. Ministry of Health: Delhi.

Nicholas, D. D., Ampofo, D. A., Ofosu-Amaah, S., Asante, R. O., and Neumann, A. (1976). Attitudes and practices of traditional birth attendants in rural Ghana: implications for training in Africa. Bulletin, 54, 343-348.

Sapru, R., Chuttani, C. S., Srivastava, A. B. L. (1974). The coverage and quality of urban maternal health programmes rendered through a MCH/FP centre-an evaluatory study. Nihae Bulletin, 7, 261-287. 